\title{
Consolidation of small and medium mining business in the gold mining industry of the Russian Far East
}

\author{
Irina Kradenykh $^{1 *}$ \\ ${ }^{1}$ Mining Institute of Far eastern branch of Russian Academy of Sciences, Khabarovsk, Russia
}

\begin{abstract}
The gold mining industry of the Russian Far East has a great development potential, whose economic growth largely depends on the efficiency of developing a unique mineral resource base. To do this, it is necessary to solve a number of tasks, including the management and organization of economic activities of enterprises engaged in the extraction of placer gold in medium and small volumes. Gold mining companies themselves positively assess the prospects for the development of the industry, despite the preservation of external restrictions imposed by Western countries. At the same time, the current position of the modern gold mining industry is determined not only by the state of the Russian economy, but also by a number of branch features related to the management of gold mining at the enterprise level. At the present time, there are increasing questions about the feasibility of consolidation of small and medium mining enterprises, which will allow them to overcome current trends in the economic development of the industry, by combining their own resources. At the same time, in practice, reverse phenomena are observed, indicating that the industry is segmented and the number of mining companies developing placer deposits is gradually increasing. However, consolidation processes, in the form of integration associations, represent one of the directions of development and effective functioning of Russian gold mining enterprises, therefore they require comprehensive research and remain relevant.
\end{abstract}

\section{Introduction}

The position of the domestic gold mining industry is determined not only by the state of the Russian economy, but a number of industry features in the management of gold mining at the enterprise level. Currently, in the placer sector, small and medium-sized enterprises have accumulated a lot of problems associated with insufficient resources, both for conducting their activities and for lobbying their own interests at the state level.

There are various ways of development for this group of companies. For example, an increase in the share of small and medium-sized gold mining enterprises, taking into account the provision of comprehensive state support. The next area is the consolidation of

*Corresponding author: kradenyh_igd@mail.ru 
small mining companies, which will allow them to continue to be able to influence the strategic development of the industry.

\section{Theoretical and practical aspects of the problem}

Currently, the processes that form the domestic gold mining, correspond to the trends inherent in the global mining industry. Analysis of the development of the Russian gold mining industry shows that the restructuring carried out in it is based on the consolidation and creation of new gold mining enterprises in the integration processes of vertical and horizontal orientation (table 1).

Table 1. Gold production by the largest Russian enterprises and companies that are part of them

\begin{tabular}{|c|c|c|c|c|c|c|}
\hline \multirow{2}{*}{ Enterprise } & \multirow{2}{*}{ Subsidiaries } & \multicolumn{5}{|c|}{ Gold production, thous. troy ounces } \\
\hline & & 2013 & 2014 & 2015 & 2016 & 2017 \\
\hline \multirow{4}{*}{ Polyus Gold } & CJSC "ZDK "Polyus" & \multirow{4}{*}{1652} & \multirow{4}{*}{1696} & \multirow{4}{*}{1763} & \multirow{4}{*}{1968} & \multirow{4}{*}{2160} \\
\hline & CJSC "Pervenets" & & & & & \\
\hline & OJSC "Lenzoloto" & & & & & \\
\hline & $\begin{array}{l}\text { LLC "GRK } \\
\text { Aldanzoloto" }\end{array}$ & & & & & \\
\hline \multirow{6}{*}{ Polymetal } & $\begin{array}{l}\text { CJSC "Serebro } \\
\text { Magadana" }\end{array}$ & \multirow{6}{*}{1282} & \multirow{6}{*}{1431} & \multirow{6}{*}{861} & \multirow{6}{*}{1269} & \multirow{6}{*}{1433} \\
\hline & $\begin{array}{l}\text { OJSC "Okhotskaya } \\
\text { GGC" }\end{array}$ & & & & & \\
\hline & $\begin{array}{l}\text { CJSC "Gold of North } \\
\text { Ural" }\end{array}$ & & & & & \\
\hline & $\begin{array}{l}\text { OJSC "Omolonskaya } \\
\text { ZRK" }\end{array}$ & & & & & \\
\hline & $\begin{array}{l}\text { OOO "Albazino } \\
\text { Resources" }\end{array}$ & & & & & \\
\hline & Amursky MMC & & & & & \\
\hline \multirow{4}{*}{ Petropavlovsk } & $\begin{array}{l}\text { OJSC "Pokrovskiy } \\
\text { rudnik" }\end{array}$ & \multirow{4}{*}{741.2} & \multirow{4}{*}{624.5} & \multirow{4}{*}{504.1} & \multirow{4}{*}{416} & \multirow{4}{*}{439,6} \\
\hline & $\begin{array}{l}\text { OOO "Malomyrkiy } \\
\text { rudnik" }\end{array}$ & & & & & \\
\hline & $\begin{array}{l}\text { OOO "Albynsky } \\
\text { Rudnik" }\end{array}$ & & & & & \\
\hline & $\begin{array}{l}\text { OJSC ZDP } \\
\text { "Koboldo" }\end{array}$ & & & & & \\
\hline
\end{tabular}

Vertical and horizontal integration processes are expressed in close production and economic relations, both between mining and metallurgical companies. Currently, almost all foreign mining companies are integrated into large companies that have the necessary capacity for the production, enrichment and processing of metals [1]. At present, the stage of initial consolidation and active formation of vertically and horizontally integrated companies at the national level is completed. However, in the gold mining industry, apart from holding structures, independent companies, including mining artels, continue to function, and they still have a significant role [2].

The experience of functioning of companies belonging to the mineral and raw materials sector confirms the interest and significance of economic integration. From the point of view of economic theory, the signs of integration are manifested in the strengthening of production and technical relations, the consolidation of capital, the joint use of resources, in creating mutually supportive conditions with the aim of increasing the aggregate economic 
productivity of economic entities. From the point of view of corporate management, the integration process involves the reorganization of business and its enterprises. Significant changes in this affect not only the organization and management of production, but also the economic behavior of the company in the market. In the economic literature, basically two forms of integration are considered: mergers and acquisitions - M\&A (mergers and acquisitions) $[3,4]$.

The prerequisites for conducting mergers and acquisitions continue to be studied both by representatives of theoretical and economic schools, and experts in the field of strategic management [5]. At the present stage, the most famous theories explaining the reasons for the mergers or acquisitions are the theory of synergy, which was put forward by the researchers M. Bradley, A. Desai, E.N. Kim in 1983. "Synergy" - the word of Greek origin, in translation denoting assistance, commonwealth, complicity. The essence of the theory is that as a result, M\&A companies acquire a wide range of different advantages by combining the resources of the companies participating in the transaction [4]. At present, the theory of synergy is considered the most confirmed by both theorists and practitioners in the field of mergers and acquisitions. It should be noted that for successful management of synergistic effects it is necessary to know the sources of their origin.

The impact of synergy is primarily aimed at a qualitative change in the system, with the transformation of the conditions, structure and mechanism of interaction of its elements, resulting in a change in the output characteristics of the system.

Considering as an object of study the organization of the activities of mining artels, it is necessary to take into account a number of differences from the generally accepted operating regimes in other industries. For example, because of climatic conditions development of deposits by open way is only possible in the warmer months. At the same time, development is carried out in hard-to-reach areas located far from developed infrastructure and settlements. Delivery of the necessary goods is carried out mainly in the winter on the so-called winter road (temporary roads). The creation of social infrastructure in the development of the field with a mining period of less than 7 years is considered economically impractical. Due to the fact that the current conditions of production are characterized by the exhaustion of the richest and most favorable for the development of placer gold reserves, mining enterprises are forced to involve poor or very poor goldbearing ores, which becomes appropriate in the period of high prices in the market of precious metals.

Currently, about 500 enterprises are engaged in the extraction of alluvial gold on the territory of the Russian Federation. In the Far Eastern Federal District, the leaders in the extraction of precious metals are the Chukotka Autonomous District, the Republic of Sakha (Yakutia), the Magadan and Amur Regions and the Khabarovsk Region. The number of enterprises extracting placer gold in the Far Eastern Federal District is shown in Fig. 1 


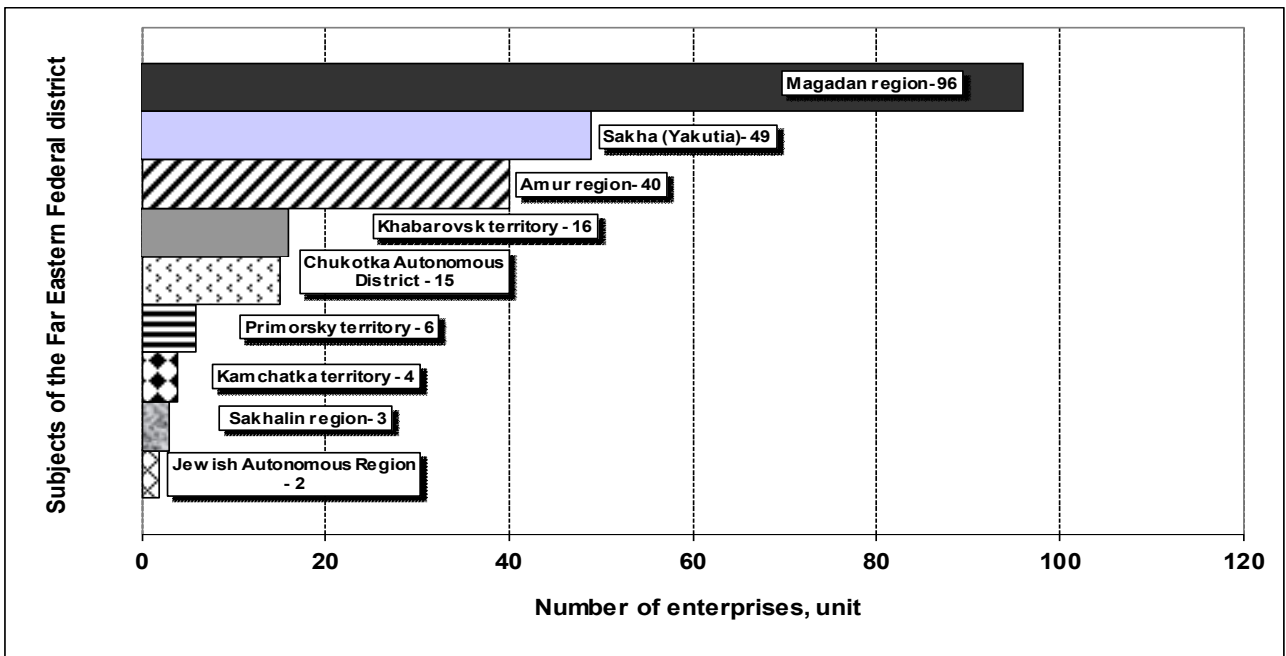

Fig. 1. The number of enterprises extracting placer gold in the Far East

Trends in the development of the gold mining industry of the Far Eastern region can be considered by the example of the Khabarovsk region, the gold content of which is mainly represented by small alluvial deposits.

Some of them, it would be more correct to call "objects of account", since they often represent fragments of previously worked out large-scale placers. The balance reserves of small and medium deposits in the province, as a rule, do not exceed $120 \mathrm{~kg}$ [2].

At the present time, enterprises that have been formed on the basis of mining artels, for example, the Amur miners' artel, which produces several tons of gold and platinum annually, continue to work successfully here. Also in the province there are also some production cooperatives, which, according to their organizational structure, are artels. For example, the team of prospectors "Vostok" continues to support the principles of joint work based on the common interest of members of the cooperative. Currently, 19 companies are mining in the region, five of which are developing ore deposits and 14 companies are steadily developing placer deposits.

The gradual depletion of the mineral and raw materials base of alluvial gold and the weak supply of active reserves due to long-term lag in the rate of growth inhibit the development of gold mining enterprises. The objective need to engage in the development of a large number of small deposits and increase on this basis the efficiency of the functioning of small and mediumgold mining enterprises can have a positive impact on the preservation and development of regional infrastructure in areas of traditional alluvial gold mining $[7,8]$. In connection with these requires an in-depth study of the management and organization of economic activities of artel prospectors.

In our opinion, in the current conditions, the stable operation of medium-sized and small gold mining enterprises is possible in the case of consolidation either with each other or with larger companies. Horizontal integration is likely to be an objective process of the further stage of development of small and medium Russian gold mining business. The implementation of horizontal integration will allow the reorganized enterprises to expand their own raw materials, provide a higher level of production and become more attractive to investors.

\section{Results and discussion}

As already mentioned, the goal of companies that have decided to implement the integration process through $\mathrm{M} \& \mathrm{~A}$ is to obtain synergistic effects that simultaneously affect 
the satisfaction of the requests of all stakeholders (shareholders, staff, customers, authorities). Within the framework of gold mining enterprises, who decided to combine their activities through horizontal integration, the following potential synergetic effects should be considered:

- pooling of company funds to purchase more efficient, expensive mining equipment;

- $\quad$ centralization of such types of work as supply, accounting, records management, work related to staff development, etc. In this case, both managerial and operational synergies are achieved through the creation of a new management system and a reduction in operating expenses by combining various services of an integrated company;

- $\quad$ improving the efficiency of work with suppliers, which will allow the combined companies to centralize the necessary purchases and to be able to use any discounts that apply to purchase prices. This aspect is relevant for gold mining companies, because the seasonal nature of the work requires advanced purchase of materials, fuel, spare parts, various mining equipment, etc. In this case, an operational synergetic effect is possible, which occurs due to savings in the implementation of costs aimed at maintaining the current activities of the gold mining enterprise;

- $\quad$ expanding the range of extracted raw materials, by involving not only gold sands, but also other natural components used in various spheres of the national economy, for example, as materials for road construction (such as gravel, etc.). With further processing, the dumps of alluvial deposits are suitable for composites, it is also possible to obtain products for the production of paints or iron ore raw materials, etc.;

- improving creditworthiness is an important for the integrated gold mining company motive based on its size, which allows a larger enterprise to have preferred positions in obtaining bank loans;

- $\quad$ expansion of the commodity portfolio by combining existing licenses or pooling financial resources to acquire additional licenses, which will strengthen the position of the company and ensure its long-term functioning. In this case, a financial synergetic effect is expected that contributes to an increase in cash flows and a reduction in business risks;

- development of poorly developed types of deposits, which will allow the integrated enterprise to strengthen competitive advantages in the long term. Since the richest placer deposits have been developed in the present period, the problem of gold reserves replenishment becomes very urgent. Horizontal integration involves the integration of technical, technological, human and financial resources. As a result, the company has the opportunity to develop previously poorly absorbed non-traditional types of placers (deepseated, technogenic), the development of which was previously carried out in limited quantities due to complex geological and technical conditions. In this case, not only organizational, but also managerial synergy is possible because of the economy of funds and the increase in cash flows due to the growth in gold production.

Undoubtedly, for the emergence of synergistic effects, it is not enough to unite companies and create a common technological chain of material and technical resources and equipment. The success of the integration strategy depends on the fulfillment of a number of conditions. Of great importance is the social basis, expressed in the methods of management and the creation of a favorable social climate. The synergetic effect is especially pronounced in the presence of joint goals and agreements in the actions between business owners and managers who are moving towards their achievement. In the absence of a system of motivations for the staff of employees of the merged companies, the effectiveness of the overall work is reduced. A negative synergetic effect is possible with a sharp change in the organizational structures of existing companies, which can lead to the loss of individual managerial experience and knowledge. Therefore, the high importance of adapting the organizational structure to the new working conditions, which will save not 
only a significant part of management developments, but also to introduce new effective elements of the structure in the parent company.

\section{Conclusions}

As a result of the study, prospects for the development of gold mining enterprises are outlined. A strategy for consolidating existing small and medium-sized enterprises should be identified through their horizontal integration. Its essence is expressed in the intensity of interaction and deepening of production and technical ties, connecting the potentials of enterprises, complementing each other, in the joint use of resources, as well as in ensuring mutually favorable conditions for the implementation of economic activities. After all, the depletion of the mineral resource base of alluvial gold and the weak provision of active reserves due to the long-term lag in the growth rate, constrain the development of gold mining enterprises.

In our opinion, the support of small and medium-sized mining business should be attributed to the priority areas of the industry, as available on the state balance of more than 5 thousand small placer deposits with reserves of about 1132 tons of gold, the most suitable for the development of small gold mining companies This fact is an integral part of the overall strategy of optimization of alluvial gold mining in the region. The objective need to involve a large number of small deposits in the development and increase the efficiency of small and medium-sized gold mining enterprises on this basis can have a positive impact on the preservation and development of regional infrastructure in the areas of traditional alluvial gold mining.

\section{References}

1. YU. A. Arhipova. Mountain information and analytical bulletin. S2I. 374-388 (2016).

2. I.A. Kradenykh, V.S.Litvintsev. News of higher educational institutions. Mining journal. 7. 34-41. (2016)

3. A.E. Molotnikov. Mergers and acquisitions: Russian experience. 344 p. (2006).

4. O N. Misko. International economic integration. 174 p. (2015).

5. V V. Obuhovskij. The economy of the XX century. 1. 27-46. (2007).

6. S G.Kashuba, V. N.Ivanov, N. V. Dudkin. Gold and technology. 3(25). 6-15. (2014).

7. I.A. Kradenyh. Mountain information and analytical bulletin (scientific and technical journal). 524. 390-401. (2017).

8. S.B. Avdasheva, V.V.Golikova, T. G.Dolgopyatova Integration processes, corporate governance and management in Russian companies. 197 p. (2006). 